\title{
Tubiferic Acid, a New 9,10-Secocycloartane Triterpenoid Acid Isolated from the Myxomycete Tubulifera arachnoidea
}

\author{
Yukihito Ippongi, ${ }^{a}$ Takashi Ohtsuki, ${ }^{a}$ Kazufumi Toume, ${ }^{a}$ Midori A. AraI, ${ }^{a}$ Yukinori Yamamoto, ${ }^{b}$ and \\ Masami ISHIBASHI ${ }^{*}, a$ \\ ${ }^{a}$ Graduate School of Pharmaceutical Sciences, Chiba University; 1-33 Yayoi-cho, Inage-ku, Chiba 263-8522, Japan: and \\ ${ }^{b}$ Yamamoto Laboratory; 1010-53 Ohtsu-ko, Kochi 781-5102, Japan. \\ Received September 11, 2010; accepted November 8, 2010; published online November 9, 2010
}

Tubiferic acid (1), a new triterpenoid acid having a 2,6-dimethyl-4,5-dihydroxy-2-hexenoic acid moiety as a side chain, was isolated from field-collected fruit bodies of the myxomycete Tubulifera arachnoidea, and its structure was elucidated by spectral data. Tubiferic acid (1) had the same unique 9,10-secocycloartane carbon skeleton as tubiferal A (2).

Key words myxomycete; Tubulifera arachnoidea; triterpenoid; 9,10-secocycloartane

During our search for bioactive natural products from myxomycetes, ${ }^{1)}$ we have recently isolated a number of new bioactive secondary metabolites such as a chlorinated polyene-pyron ${ }^{2)}$ and a naphthoquinone pigment. ${ }^{3)}$ In 2004 we reported isolation of a cytotoxic triterpenoid aldehyde lactone, named tubiferal A (2), having a unique triterpenoid carbon skeleton with a consecutive 6-7-6-5 ring system, from field-collected fruit bodies of Tubifera dimorphotheca. ${ }^{4)} \mathrm{We}$ recently investigated field-collected fruit bodies of Tubulifera arachnoidea (=Tubifera ferruginosa), and here we describe the isolation and structure elucidation of a new triterpenoid acid, named tubiferic acid (1). This compound (1), with a 2,6-dimethyl-4,5-dihydroxy-2-hexenoic acid moiety as a side chain, had the same unique triterpenoid carbon skeleton as tubiferal A (2).

\section{Results and Discussion}

Fruit bodies of the myxomycete Tubulifera arachnoidea were extracted with $\mathrm{MeOH}$, and the EtOAc-silane fraction of the $\mathrm{MeOH}$ extract was subjected to octadecyl silane (ODS) column chromatography to give a new compound, tubiferic acid (1), in $0.016 \%$ yield.

The molecular formula of $\mathbf{1}$ was suggested to be $\mathrm{C}_{30} \mathrm{H}_{46} \mathrm{O}_{5}$ by high resolution-electrospray ionization (HR-ESI)-MS data $\left[\mathrm{m} / \mathrm{z} \quad 485.3294(\mathrm{M}-\mathrm{H})^{-}, \Delta+2.2 \mathrm{mmu}\right.$. Compound $\mathbf{1}$ showed IR absorption bands at 3410 and $1700 \mathrm{~cm}^{-1}$, implying the presence of hydroxyl and carboxyl groups. The ${ }^{1} \mathrm{H}-$ NMR spectrum of 1 in $\mathrm{CD}_{3} \mathrm{OD}$ (Table 1) showed signals due to one secondary methyl $\left(\delta_{\mathrm{H}} 0.93, \mathrm{~d}, J=6.6 \mathrm{~Hz}\right)$ and five tertiary methyl groups at $\left(\delta_{\mathrm{H}} 0.77,0.78,0.91,1.04,1.89\right)$, three $s p^{3}$ oxymethines $\left(\delta_{\mathrm{H}} 3.39,3.50,4.30\right)$, and two $s p^{2}$ methines $\left(\delta_{\mathrm{H}} 5.23,6.66\right)$. The ${ }^{13} \mathrm{C}-\mathrm{NMR}$ spectrum revealed signals of six olefinic carbons $\left(\delta_{\mathrm{C}} 121.7,129.6,132.1,137.8,138.3\right.$, 143.3) and one carboxyl group $\left(\delta_{\mathrm{C}} 172.2\right)$, thus accounting for four out of eight unsaturation degrees. The remaining four were therefore ascribable to four rings.

Analysis of the 2D-NMR data of $\mathbf{1}$ (Fig. 1) showed the presence of three partial structures, $\mathbf{A}, \mathbf{B}$, and $\mathbf{C}$. The ${ }^{1} \mathrm{H}-{ }^{1} \mathrm{H}$ correlation spectroscopy (COSY) spectrum showed proton connectivities for $\mathrm{H}_{2}-1 / \mathrm{H}_{2}-2 / \mathrm{H}-3, \mathrm{H}_{2}-6 / \mathrm{H}_{2}-7 / \mathrm{H}-8$, and $\mathrm{H}-$ $11 / \mathrm{H}_{2}-12$ for the partial structure $\mathbf{A}$, and a proton network for $\mathrm{H}_{2}-15 / \mathrm{H}_{2}-16 / \mathrm{H}-17 / \mathrm{H}-20\left(\mathrm{H}_{3}-21\right) / \mathrm{H}-22 / \mathrm{H}-23 / \mathrm{H}-24$ in partial structure $\mathbf{C}$ was also suggested from the ${ }^{1} \mathrm{H}-{ }^{1} \mathrm{H}$ COSY spec-
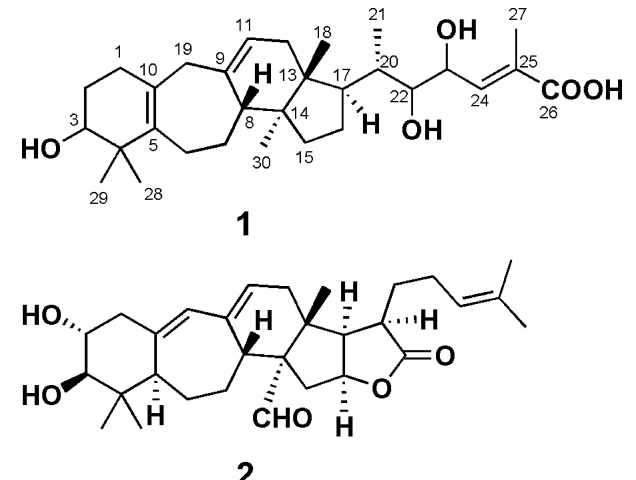

2

Table 1. ${ }^{1} \mathrm{H}$ - and ${ }^{13} \mathrm{C}-\mathrm{NMR}$ Spectral Data of Tubiferic Acid (1) in $\mathrm{CD}_{3} \mathrm{OD}$

\begin{tabular}{rlr}
\hline \hline Position & \multicolumn{1}{c}{$\delta_{\mathrm{H}}(J \mathrm{in} \mathrm{Hz})$} & \multicolumn{1}{c}{$\delta_{\mathrm{C}}$} \\
\hline 1 & $2.15(\mathrm{~m}), 2.00(\mathrm{~m})$ & 30.8 \\
2 & $1.66(\mathrm{~m}, \alpha-\mathrm{H}), 1.38(\mathrm{~m}, \beta-\mathrm{H})$ & 28.3 \\
3 & $3.39(\mathrm{dd}, 10.9,3.4)$ & 76.9 \\
4 & & 40.9 \\
5 & & 138.3 \\
6 & $2.36(\mathrm{~m}, \alpha-\mathrm{H}), 2.26(\mathrm{~m}, \beta-\mathrm{H})$ & 28.1 \\
7 & $1.47(\mathrm{~m}), 1.57(\mathrm{~m})$ & 26.5 \\
8 & $2.21(\mathrm{~m})$ & 47.5 \\
9 & & 137.8 \\
10 & & 129.6 \\
11 & $5.23(\mathrm{brd}, 5.0)$ & 121.7 \\
12 & $1.93(\mathrm{brd}, 5.0, \alpha-\mathrm{H}), 2.14(\mathrm{~m}, \beta-\mathrm{H})$ & 38.8 \\
13 & & 45.9 \\
14 & $1.38(\mathrm{~m})(2 \mathrm{H})$ & 48.6 \\
15 & $1.67(\mathrm{~m}), 1.96(\mathrm{~m})$ & 34.4 \\
16 & $2.07(\mathrm{~m})$ & 27.6 \\
17 & $0.77(\mathrm{~s})(3 \mathrm{H})$ & 48.0 \\
18 & $2.64(\mathrm{~d}, 14.0), 2.74(\mathrm{~d}, 14.0)$ & 15.3 \\
19 & $1.91(\mathrm{~m})$ & 42.9 \\
20 & $0.93(\mathrm{~d}, 6.6)(3 \mathrm{H})$ & 37.6 \\
21 & $3.50(\mathrm{dd}, 9.0,1.4)$ & 12.0 \\
22 & $4.30(\mathrm{t}, 9.0)$ & 76.5 \\
23 & $6.66(\mathrm{dd}, 9.0,1.4)$ & 69.0 \\
24 & & 143.3 \\
25 & $1.89 \mathrm{~d}(1.4)(3 \mathrm{H})$ & 132.1 \\
26 & $1.04 \mathrm{~s}(3 \mathrm{H})$ & 172.2 \\
27 & $0.91 \mathrm{~s}(3 \mathrm{H})$ & 13.4 \\
28 & $0.78 \mathrm{~s}(3 \mathrm{H})$ & 25.4 \\
29 & & 20.7 \\
30 & & 18.5 \\
\hline
\end{tabular}




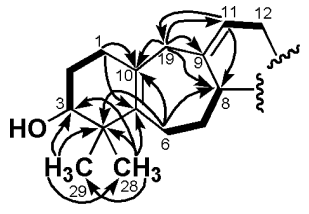

A

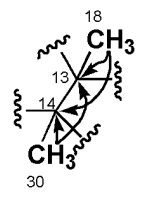

B

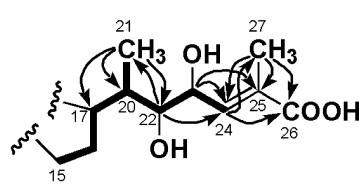

C
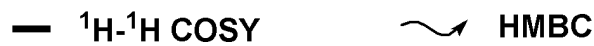

Fig. 1. Three Partial Structures $(\mathbf{A}-\mathbf{C})$ and Key 2D-NMR Data for Compound 1

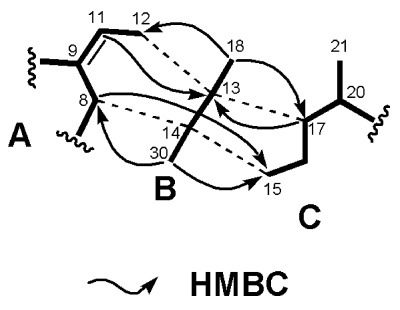

Fig. 2. Connection of Three Partial Structures $(\mathbf{A}-\mathbf{C})$ by HMBC Correlations

trum. The heteronuclear multiple bond connectivity (HMBC) spectrum of 1 revealed the key correlations for $\mathrm{H}_{2}-1 / \mathrm{C}-10$, $\mathrm{H}_{2}-1 / \mathrm{C}-5, \mathrm{H}_{3}-28 / \mathrm{C}-3, \mathrm{H}_{3}-28 / \mathrm{C}-4, \mathrm{H}_{3}-28 / \mathrm{C}-5, \mathrm{H}_{3}-29 / \mathrm{C}-3, \mathrm{H}_{3}-$ 29/C-4, H $-6 / \mathrm{C}-4, \mathrm{H}_{2}-6 / \mathrm{C}-8, \mathrm{H}_{2}-6 / \mathrm{C}-10, \mathrm{H}_{2}-19 / \mathrm{C}-9, \mathrm{H}_{2}-19 / \mathrm{C}-$ $10, \mathrm{H}_{2}-19 / \mathrm{C}-11, \mathrm{H}-11 / \mathrm{C}-8$, and $\mathrm{H}-11 / \mathrm{C}-19$, leading to the partial structure $\mathbf{A}$. The HMBC correlations for $\mathrm{H}_{3}-18 / \mathrm{C}-13$, $\mathrm{H}_{3}-18 / \mathrm{C}-14, \mathrm{H}_{3}-30 / \mathrm{C}-13$, and $\mathrm{H}_{3}-30 / \mathrm{C}-14$ suggested the partial structure $\mathbf{B}$, while the HMBC correlations for $\mathrm{H}_{3}-21 / \mathrm{C}$ $17, \mathrm{H}_{3}-21 / \mathrm{C}-20, \mathrm{H}_{3}-21 / \mathrm{C}-22, \mathrm{H}-22 / \mathrm{C}-21, \mathrm{H}-22 / \mathrm{C}-24, \mathrm{H}-$ 23/C-24, H-23/C-25, H-24/C-26, H-24/C-27, $\mathrm{H}_{3}-27 / \mathrm{C}-24$, $\mathrm{H}_{3}-27 / \mathrm{C}-25$, and $\mathrm{H}_{3}-27 / \mathrm{C}-26$ corroborated the partial structure $\mathbf{C}$.

These three partial structures were then connected by further analysis of the HMBC spectral data, as shown in Fig. 2. Partial structures A and $\mathbf{B}$ were connected between C-12 and $\mathrm{C}-13$ positions and between $\mathrm{C}-8$ and $\mathrm{C}-14$ positions on the basis of the HMBC correlations observed for $\mathrm{H}_{3}-18 / \mathrm{C}-12$, $\mathrm{H}_{3}-30 / \mathrm{C}-8$, and $\mathrm{H}-11 / \mathrm{C}-13$, where as partial structures $\mathbf{B}$ and $\mathrm{C}$ were connected at $\mathrm{C}-14$ and $\mathrm{C}-15$ positions and at $\mathrm{C}-13$ and $\mathrm{C}-17$ positions by $\mathrm{HMBC}$ cross peaks for $\mathrm{H}_{3}-18 / \mathrm{C}-17$, $\mathrm{H}_{3}-30 / \mathrm{C}-15$, and $\mathrm{H}-17 / \mathrm{C}-13$. HMBC correlation observed from $\mathrm{H}-8$ to $\mathrm{C}-15$ also supported the connection of these partial structures, suggesting that C-8 in partial structure $\mathbf{A}$ was correlated with $\mathrm{C}-15$ in partial structure $\mathbf{C}$ through $\mathrm{C}-14$ in partial structure $\mathbf{B}$.

From the results described above, the whole planar structure of tubiferic acid was constructed as $\mathbf{1}$, which possesses the same carbon skeleton with a 6-7-6-5 ring system contained in tubiferal A (2); this carbon skeleton may correspond to a 9,10-secocycloartane. ${ }^{5,6)}$

The hydroxyl group on the C-3 position of 1 was suggested to be equatorially oriented, since the $\mathrm{H}-3$ signal was observed as a doublet of doublet $(J=10.9,3.4 \mathrm{~Hz})$, implying that $\mathrm{H}-3$ was $\alpha$-axial and coupled with the $2 \beta$-axial hydrogen of C-2 with a large coupling constant $(10.9 \mathrm{~Hz})$. This assignment was also supported by nuclear Overhauser effect (NOE) observations from $\mathrm{H}-3$ to $\mathrm{H}-2 \alpha\left(\delta_{\mathrm{H}} 1.66\right)$ and $\mathrm{H}_{3}-28$ ( $\alpha$-equatorial methyl group attached on C-4) as shown in Fig. 3a. The

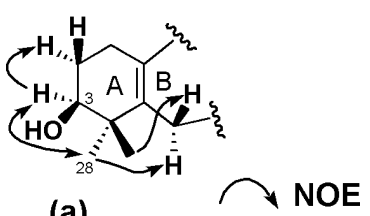

(a)

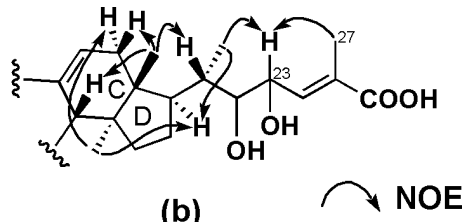

(b)
Fig. 3. Assignment of NOE Correlations Observed for Compound $\mathbf{1}$

Stereochemical relationship between $\mathrm{A} / \mathrm{B}$ and $\mathrm{C} / \mathrm{D}$ rings is arbitrary.

geometry of the $\Delta^{24,25}$-double bond was assigned as $Z$ on the basis of the high-field resonance of the C-27 methyl carbon $\left.\left(\delta_{\mathrm{C}} 13.4\right)^{7}\right)$ as well as the NOE correlation observed from $\mathrm{H}_{3}$ $27\left(\delta_{\mathrm{H}} 1.89\right)$ to $\mathrm{H}-23\left(\delta_{\mathrm{H}} 4.30\right)$. NOE correlations observed for other positions were assigned as shown in Fig. 3, on which bases we propose that the stereochemistry of C/D rings of 1 was parallel to that of tubiferal A (2), although the stereochemistry of a diol moiety in the side chain of $\mathbf{1}$ remains undefined. Since we could not obtain the NOE correlations between $\mathrm{A} / \mathrm{B}$ and $\mathrm{C} / \mathrm{D}$ rings, their stereochemical relationship is arbitrary.

\section{Experimental}

General Optical rotations were measured with a JASCO P-1020 polarimeter. IR spectra were measured on ATR in a JASCO FT-IR 230 spectrophotometer. UV spectra were measured in a Shimadzu UV mini-1240 spectrometer. NMR spectra were recorded on JEOL JNM-A400 and JEOL JNM-ECP600 spectrometers with a deuterated solvent, the chemical shift of which was used as an internal standard. HR-ESI-MS were obtained on an Exactive (Thermo Scientific, Japan).

Organisms Fruit bodies of Tubulifera arachnoidea were collected and identified by Y.Y. in Konan-shi, Kochi Prefecture, Japan, in July 2008. A voucher specimen (\#31366) is maintained by Y.Y. (Yamamoto Lab., Kochi, Japan).

Extraction and Isolation Air-dried fruiting bodies of Tubulifera arachnoidea $(30.1 \mathrm{~g})$ were extracted with $\mathrm{MeOH}(100 \mathrm{ml} \times 3)$, and the combined $\mathrm{MeOH}$ extracts $(1.24 \mathrm{~g})$ suspended in $10 \%$ aqueous $\mathrm{MeOH}(100 \mathrm{ml})$ were partitioned with hexane $(1300 \mathrm{ml} \times 3)$, EtOAc $(100 \mathrm{ml} \times 3)$ and $n$-BuOH $(100 \mathrm{ml} \times 3)$ to give four fractions, a hexane layer $(102 \mathrm{mg})$, EtOAc layer $(211 \mathrm{mg}), n-\mathrm{BuOH}$ layer $(346 \mathrm{mg})$, and water layer $(612 \mathrm{mg})$. The EtOAcsoluble fraction $(193 \mathrm{mg}$ ), which was positive for anisaldehyde reagent by TLC examination, was subjected to ODS column chromatography $(2.0 \times$ $27.5 \mathrm{~cm}$, Chromatorex ODS C18; Fuji Silysia Chemical Ltd., Japan) eluted with $70-100 \% \mathrm{MeOH}$ in water to give compound $1(4.8 \mathrm{mg})$ in the fraction eluted with $83 \% \mathrm{MeOH}$ in water. By TLC examination using anisaldehyde reagent as well as crude ${ }^{1} \mathrm{H}$-NMR spectral analysis, $\alpha$-spinasterol $\left.{ }^{8}\right)(3.7 \mathrm{mg})$ was obtained from less polar fraction of the same ODS column eluted with $\mathrm{MeOH} / \mathrm{CHCl}_{3}(80: 20)$. From the $n-\mathrm{BuOH}$ soluble fraction, D-trehalose ${ }^{9)}$ $(9.0 \mathrm{mg})$ was isolated by Sephadex LH-20 column chromatography $(14 \times$ $620 \mathrm{~mm}, 100 \% \mathrm{MeOH})$.

Tubiferic Acid (1): Colorless solid; $[\alpha]_{\mathrm{D}}^{19}+19.5(c=0.5, \mathrm{MeOH})$; IR $v_{\max }$ (ATR) $3410,2940,1700,1650,1570,1460$, and $1380 \mathrm{~cm}^{-1}$; ${ }^{1} \mathrm{H}-$ and ${ }^{13} \mathrm{C}-$ NMR data in Table 1; HR-ESI-MS $m / z 485.3294[\mathrm{M}-\mathrm{H}]^{-}$, Calcd for $\mathrm{C}_{30} \mathrm{H}_{45} \mathrm{O}_{5}, 485.3272$.

Acknowledgements This work was supported by Grants-in-Aid for Scientific Research from the Japan Society for the Promotion of Science (JSPS).

\section{References and Notes}

1) Ishibashi M., Yakugaku Zasshi, 127, 1369-1381 (2007).

2) Shintani A., Ohtsuki T., Yamamoto Y., Hakamatsuka T., Kawahara N., Goda Y., Ishibashi M., Tetrahedron Lett., 50, 3189-3190 (2009).

3) Shintani A., Yamazaki H., Yamamoto Y., Ahmed F., Ishibashi M., Chem. Pharm. Bull., 57, 894-895 (2009).

4) Kamata K., Onuki H., Hirota H., Yamamoto Y., Hayashi M., Komiyama K., Sato M., Ishibashi M., Tetrahedron, 60, 9835—9839 (2004).

5) The carbon skeletons of $\mathbf{1}$ and $\mathbf{2}$ were the same as that of acerinol, 
which was an artificially generated compound from a cycloartanetriterpene by treatment with mineral acid: Kusano G., Uchida H., Murakami Y., Sakurai N., Takemoto T., Yakugaku Zasshi, 96, 321-325 (1976).

6) The fission of the cyclopropane ring for acerinol ${ }^{5)}$ was likely to be assisted by 3,10-epoxy ring formation, although it was previously reported that an acerinol-related compound was isolated from Cimicifuga heracleifolia without acid treatment: Li J. X., Kadota S., Hattori
M., Yoshimachi S., Shiro M., Oogami N., Mizuno H., Namba T., Chem. Pharm. Bull., 41, 832-841 (1993).

7) Carey L., Clough J. M., Pattenden G., J. Chem. Soc. Perkin Trans. 1, 1983, 3005-3009 (1983).

8) Furuya T., Orihara Y., Tsuda Y., Phytochemistry, 29, 2539-2543 (1990).

9) Matsuura H., Asakawa C., Kurimoto M., Mizutani J., Biosci. Biotechnol. Biochem., 66, 1576-1578 (2002). 